\title{
SISTEM INFORMASI REKRUTMEN KARYAWAN BERBASIS WEB MENGGUNAKAN ALGORITMA SAW (SIMPLE ADDITIVE WEIGHTING)
}

\author{
Nur Alamsyah \\ Fakultas Ilmu Komputer Universitas Nasional PASIM \\ Jalan Dakota No 8a. Kota Bandung Jawa Barat 40175 Telepon (022) 6072803 \\ nuralamsyah.bdg@gmail.com
}

\begin{abstract}
Penelitian ini bertujuan untuk mengembangkan sistem mengenai perekrutan karyawan. Karena pada uтитnya tahapan sistem perekrutan karyawan masih menggunakan cara sistem manual, seperti menerima dokumen lamaran calon karyawan, melakukan test psikotes secara langsung dengan memberikan soal dalam bentuk kertas. Cara seperti ini dirasa kurang efisien dikarenakan waktu yang dibutuhkan relatif lama. Salah satu cara untuk mengatasi masalah yang dipaparkan diatas adalah dengan adanya sistem informasi rekrutmen berbasis web yang mampu memberikan informasi mengenai lowongan pekerjaan untuk para calon karyawan serta tahapan proses perekrutan karyawan seperti seleksi dokumen, psikotes online, dengan pemanfaatan teknologi yang tepat, maka diharapkan dapat memberikan peningkatan dan dapat mengembang sistem yang awalnya manual menjadi sistem informasi yang lebih cepat, mudah dan efisien dalam perekrutan karyawan dengan menggunakan Sistem Pendukung Keputusan (SPK) untuk mendukung tahap pengambilan keputusan mengidentifikasi masalah, memilih data yang relevan, menentukan pendekatan yang digunakan dalam proses pengambilan keputusan yang mengginakan metode Simple Additive Weigthing (SAW). Metodelogi yang digunakan untuk merancang dan membangun sistem pendukung keputusan tersebut yaitu Ration Unified Process (RUP). Untuk perancangan digunakan Unified Modeling Languge (UML)
\end{abstract}

Kata Kunci : Rekrutmen, Karyawan, SPK, Psikotes, SAW

This research aims to develop a system of employee recruitment. Generally, the stages of employee recruitment systems still use manual system methods, such as receiving prospective employee application documents and conducting psychological tests directly by giving questions in paper form. This way is considered less efficient because it takes long time. One way to overcome the problems described above is by having a web-based recruitment information system that is able to provide information about job vacancies for prospective employees as well as the stages of the employee recruitment process such as document selection, online psychological testing. By using appropriate technology, it is expected to provide improvement and it can develop a system that is originally a manual into an information system that is faster, easier and more efficient in recruiting employees by using a Decision Support System to support the decision-making stage of identifying problems, selecting relevant data, determining the approach used in the decision making process which uses the Simple Additive Weigthing (SAW) method. The methodology used to design and build a decision support system is the Ration Unified Process (RUP). Unified Modeling Language (UML) is used for design

Keywords : CRM, Hotelmu, Object Oriented, Prototype 
JURNAL NUANSA INFORMATIKA

Volume 14 Nomor 2, Juli 2020

\section{PENDAHULUAN}

Pengelolaan Sumber Daya Manusia (SDM) merupakan hal yang penting dalam pencapaiaan tujuan. Umumnya pimpinan perusahaan mengharapkan kinerja yang baik dari masing-masing karyawan dalam mengerjakan tugas-tugas yang diberikan oleh perusahaan. Perusahaan menyadari bahwa Sumber Daya Manusia (SDM) merupakan modal dasar dalam proses pembangunan perusahaan bahkan nasional, oleh karena itu kualitas SDM senantiasa harus dikembangkan dan diarahkan agar tercapainya tujuan yang telah ditetapkan oleh perusahaan. Salah satu aktivitas dalam pengelolaan SDM adalah rekrutmen dan seleksi.

Dengan adanya kemajuan teknologi dan perkembangan ilmu pengetahuan pada saat ini sangat membantu manusia atau perusahaan dalam menyelesaikan tugasnya. Salah satunya adalah dengan memanfaatkan kemajuan teknologi untuk memudahkan dalam melakukan rekrutmen dan seleksi calon karyawan.

Trend seleksi karyawan pada kurun waktu satu dekade kebelakang yang didominasi oleh media cetak dan metode tatap muka secara langsung, kini seiring dengan perkembangan jaman dan teknologi telah bergeser menuju ke era digital, yang dirasa lebih efektif dan efisien dan dapat membantu dalam pengambilan keputusan.

Berdasarkan latar belakang masalah yang telah diuraikan diatas, dapat diidentifikasikan masalah-masalah seperti berikut :

1. Bagaimana mengembangkan sistem informasi yang dapat mengelola informasi lowongan pekerjaan

2. Bagaimana mengembangkan sistem informasi yang dapat mengelola soal-soal dan menampilkan nilai psikotes calon karyawan

3. Bagaimana mengembangkan sistem informasi yang dapat mengelola data user dan data lamaran calon karyawan

4. Bagaimana mengembangkan sistem
p-ISSN : 1858-3911, e-ISSN : 2614-5405

https://journal.uniku.ac.id/index.php/ilkom

informasi yang dapat mengelola informasi umum seputar perusahaan seperti visi misi, sejarah dan kegiatan perusahaan.

5. Bagaimana mengembangkan sistem informasi yang dapat menyediakan tes online bagi calon karyawan

\section{METODE PENELITIAN}

Pada peneltian ini metode pelaksanaanya dilakukan melalui studi pendahuluan yaitu obeservasi lapangan, dilanjutkan dengan menentukan kriteria dan pembobotan sebagai langkah proses analisis dan dilanjutkan dengan Design dan Pengembangan Sistem Informasi Rekrutmen Karyawan di PT. Pasim Sentra Utama dengan menggunakan metode SAW (Simple Additive Weighting) dan juga menggunakan model proses RUP.

\subsection{Metode pengumpulan data}

Untuk memperoleh informasi yang berhubungan dengan penelitian ini, penulis melakukan pengumpulan data-data yang diperlukan untuk melakukan pembangunan system informasi.

Metode pengumpulan data melalui 2 cara,yaitu :

a. Pengambilan data secara langsung (Fields Research)

Untuk pelaksanaan pengambilan data secara langsung ini menggunakan 2 cara yaitu :

1) Observasi Langsung, yaitu mengamati langsung ke lapangan untuk mengetahui bagaimana prosedur pembelian dan pembayaran unit oleh pembeli.

2) Wawancara, yaitu tanya jawab dengan beberapa individu dalam organisasi tersebut yang terlibat langsung dalam perekrutan calon karyawan.

b. Studi Literatur (Studi Pustaka)

Selain pengambilan data secara langsung, demi tercapainya tujuan pembangunan aplikasi sehingga memenuhi kriteria pembangunan aplikasi yang baik dan sistematis, maka penyusun juga melakukan studi literatur. Studi literatur ini dimaksudkan

Page | 32 
JURNAL NUANSA INFORMATIKA

Volume 14 Nomor 2, Juli 2020

penyusun untuk mencocokkan antara fakta yang terjadi dengan aspek-aspek yang ada dalam pembangunan sistem informasi.

\subsection{Model proses Pembangunan \\ Perangkat Lunak}

Pada penelitian ini penulis menggunakan model proses Rational Unified Process RUP) yaitu sebuah proses rekayasa perangkat lunak yang menggunakan pendekatan disiplin untuk menetapkan tugas dan tanggung jawab dalam pengembangan sistem.. RUP diciptakan, dikembangkan dan dikelola oleh Rational Software sekarang IBM. Tujuan dari RUP adalah menghasilkan perangkat lunak berkualitas tinggi yang memenuhi kebutuhan pengguna dan dapat diprediksi penjadwalan dan biaya pengembangannya. Fase yang digunakan penulis di model proses RUP yaitu inception, elaboration, contruction, Trasition.

\subsection{Metode pengembangan sistem}

Metode pendekatan sistem yang digunakan dalam pembangunan sistem informasi ini yaitu Teknik Pembangunan Sistem dengan Metode pendekatan berbasis objek (object oriented method) dan hasil analisis menggunakan UML (Unified Modeling Language).

UML adalah sebuah bahasa yang telah menjadi standar dalam industry untuk visualisasi, merancang dan mendokumentasikan sistem piranti lunak. UML menawarkan sebuah standar untuk merancang model sebuah sistem. Yang biasa diguanakan dalam UML untuk membangun sebuah sistem adalah Use case Diagram, Sequence Diagram, Class Diagram dan Activity Diagram.

\section{HASIL DAN PEMBAHASAN}

\subsection{Perancangan Aplikasi}

\subsubsection{Use Case Diagram}

Untuk mempermudah perancangan serta pembacaan Use Case, maka Use Case dipisahkan berdasarkan aktor yang terlibat. Berikut ini dijelaskan aktor apa saja yang terlibat :
p-ISSN : 1858-3911, e-ISSN : 2614-5405

https://journal.uniku.ac.id/index.php/ilkom

a) Admin (Pihak Perusahaan)

Hak akses administrator diberikan kepada admin yang bertugas untuk mengelola sistem secara keseluruhan. Admin merupakan user utama dalam sistem rekrutmen ini.

b) Pelamar

Hak akses ini diberikan kepada pelamar yang akan melakukan tes, sebelum masuk ke halaman psikotes, pelamar harus melakukan pendaftaran dan logi terlebih dahulu.

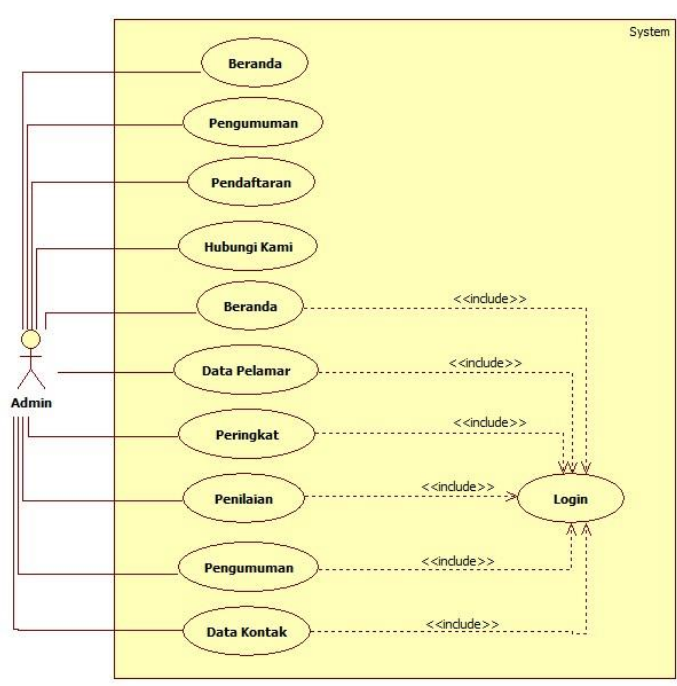

Gambar 3.1 Use Case Admin Bagian Rekrutmen

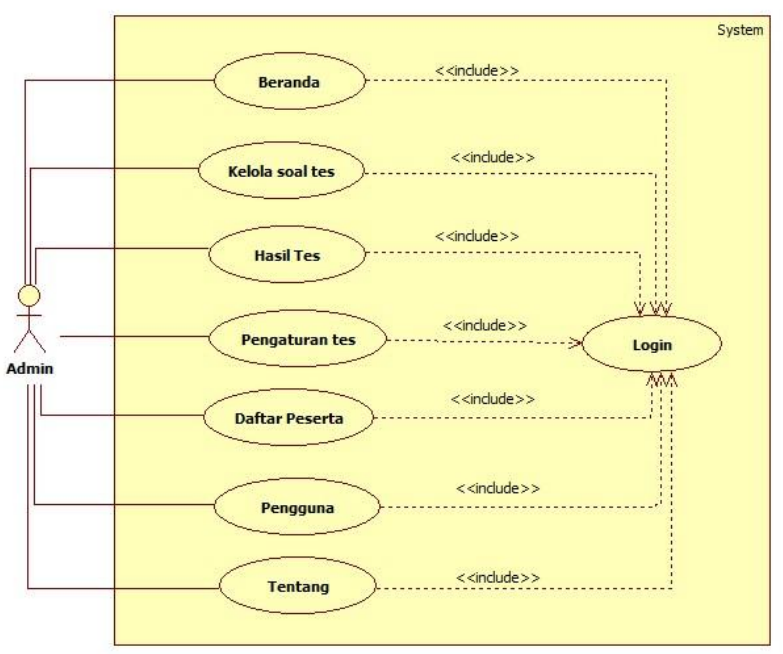

Gambar 3.2 Use Case Admin Bagian Psikotes 
JURNAL NUANSA INFORMATIKA

Volume 14 Nomor 2, Juli 2020

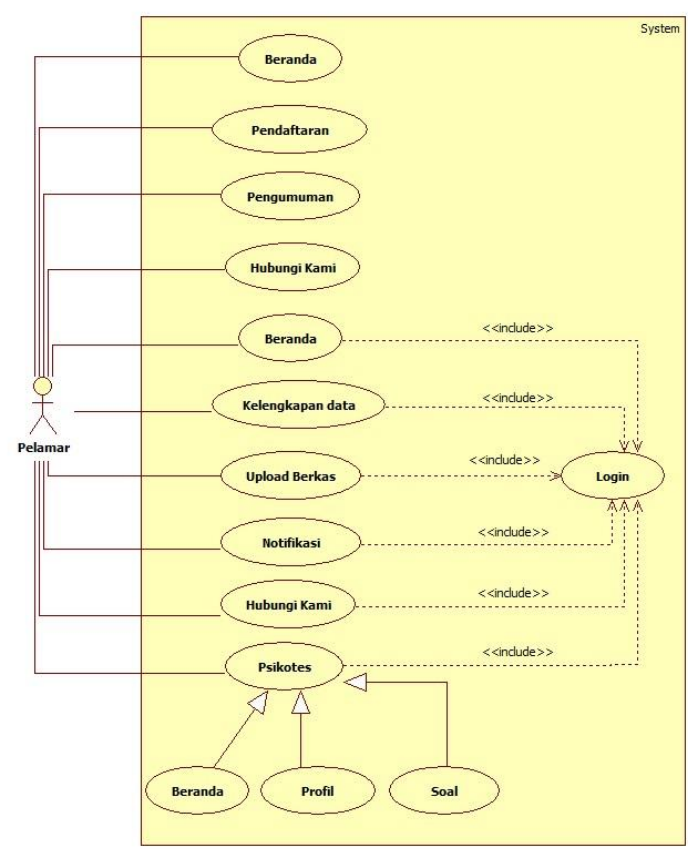

Gambar 3.3 Use Case Pelamar

\subsubsection{Activity Diagram}

a. Activity - Register

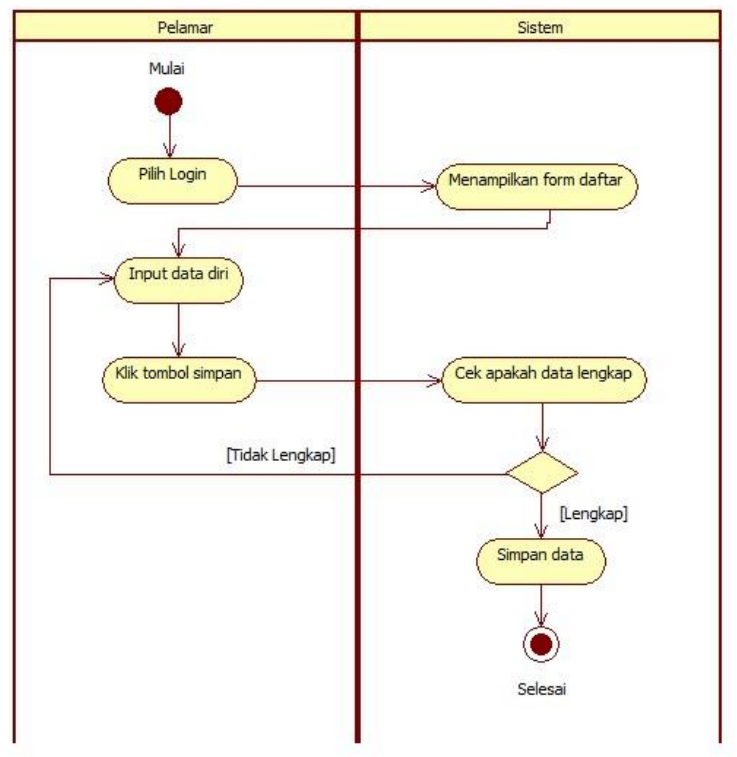

Gambar 3.4 Activity Diagram Login

b. Activity - Login
p-ISSN : 1858-3911, e-ISSN : 2614-5405

https://journal.uniku.ac.id/index.php/ilkom

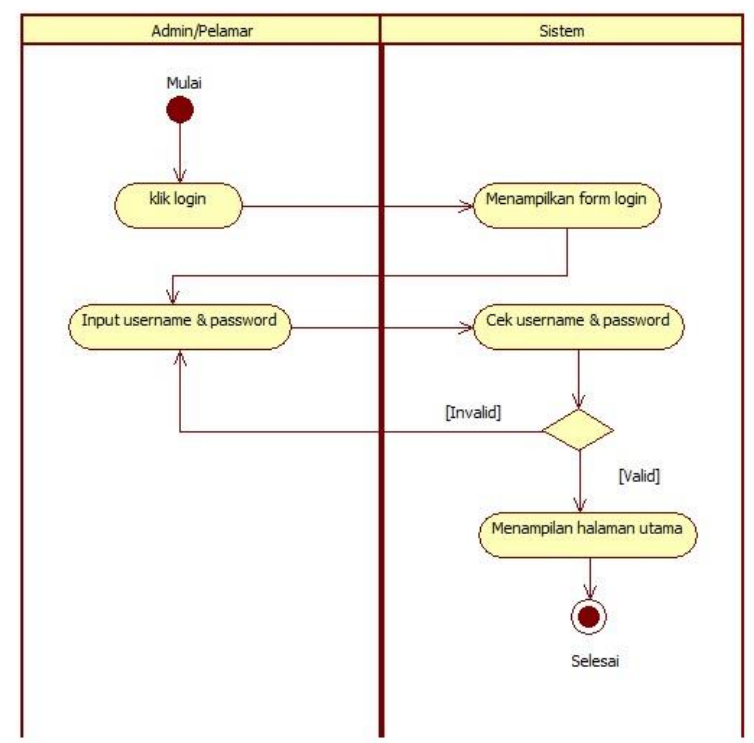

Gambar 3.5 Activity Diagram Login

c. Activity - Beranda

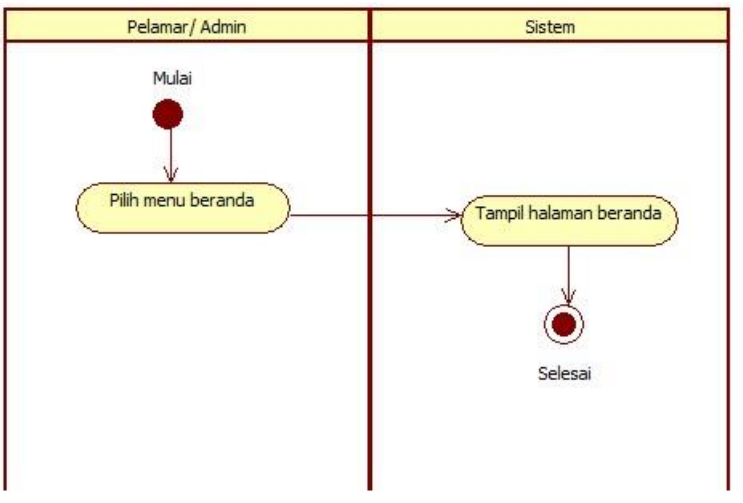

Gambar 3.6 Activity Diagram Beranda

d. Activity - Pengumuman

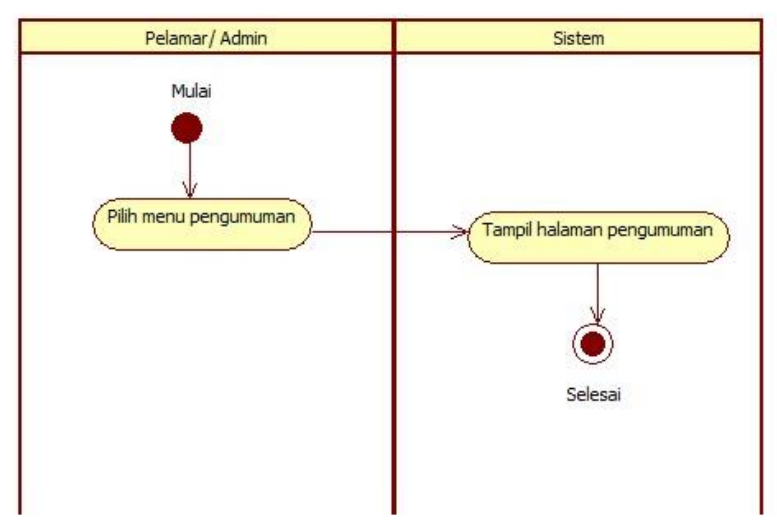

Gambar 3.7 Activity Diagram Pengumuman 
JURNAL NUANSA INFORMATIKA

Volume 14 Nomor 2, Juli 2020

\subsubsection{Sequence Diagram}

\section{a. Sequence - Lihat Beranda}

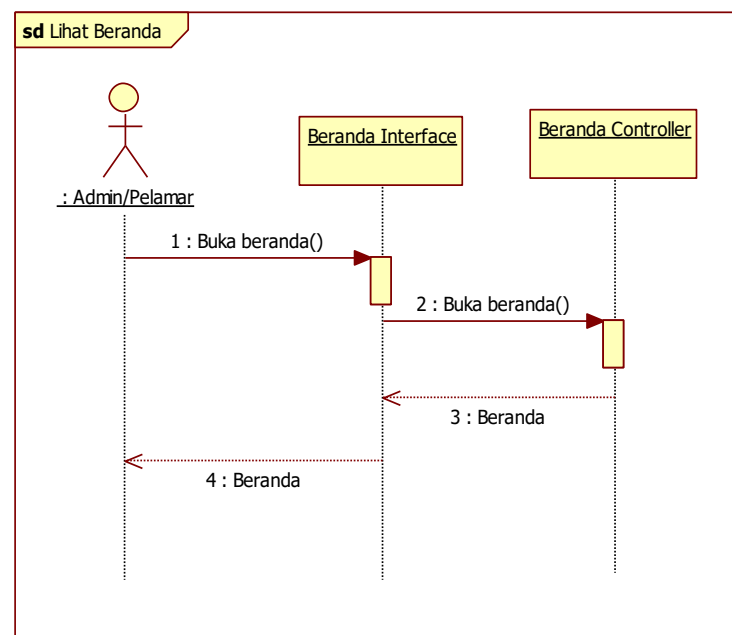

Gambar 3.8 Sequence Diagram Lihat Beranda

\section{b. Sequence - Lihat Pengumuman}

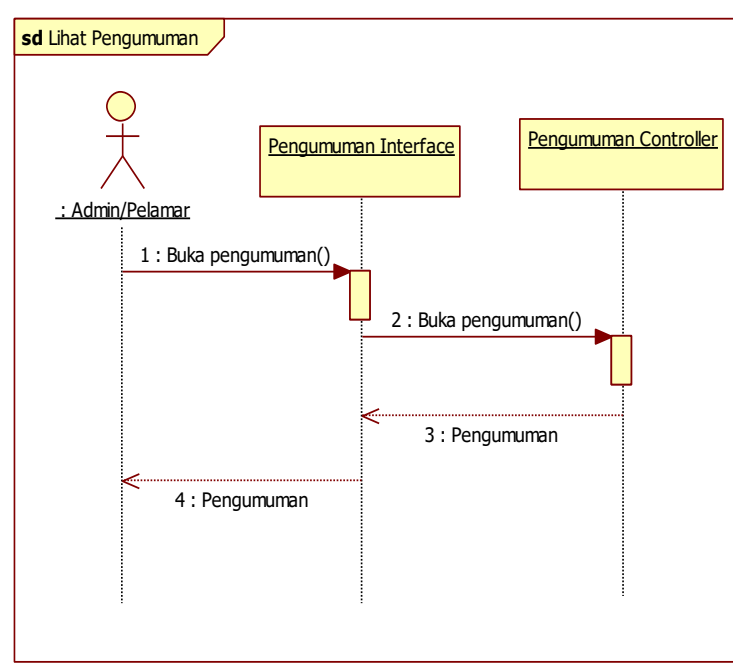

Gambar 3.9 Sequence Diagram Pengumuman

\section{c. Sequence-Hubungi Kami}

p-ISSN : 1858-3911, e-ISSN : 2614-5405

https://journal.uniku.ac.id/index.php/ilkom

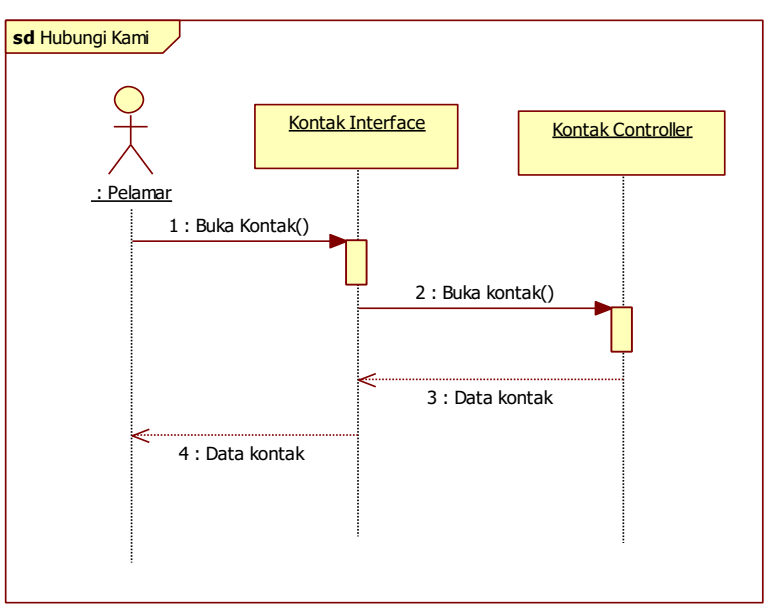

Gambar 3.10 Sequence Diagram Hubungi Kami

\subsubsection{Class Diagram}

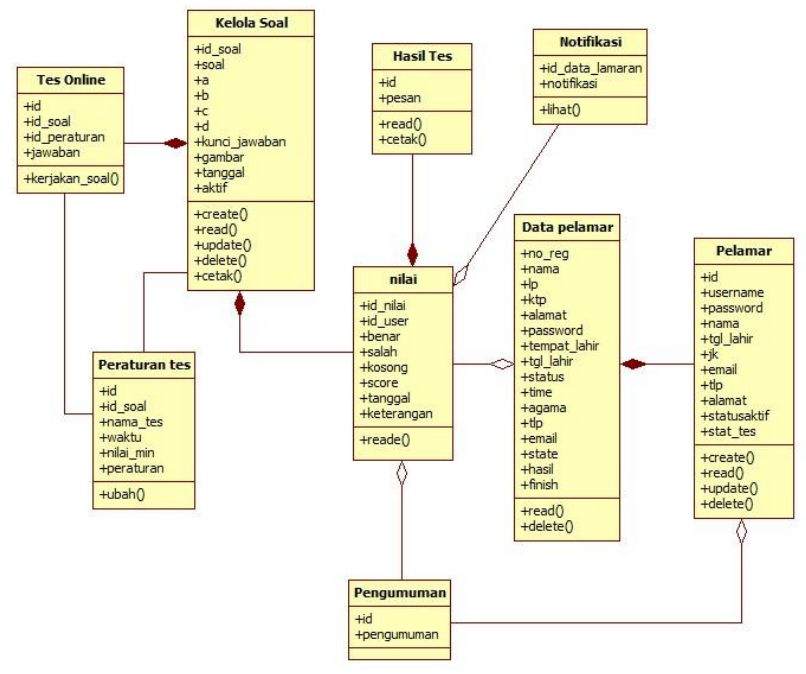

Gambar 3.11 Class Diagram

\subsection{Hasil}

1. Tampilan Utama

Berikut ini merupakan tampilan utama dari sistem informasi rekrutmen karyawan:

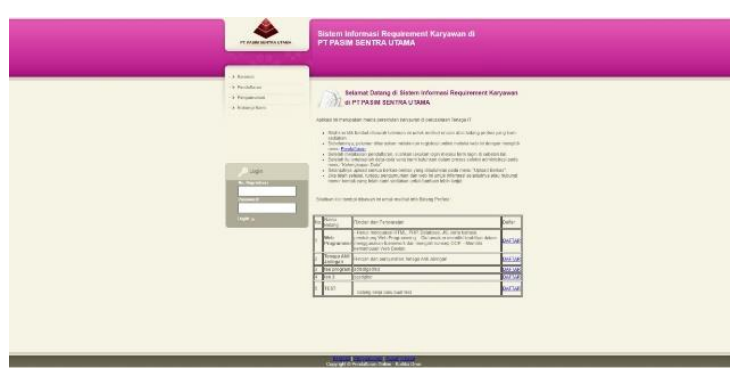

Gambar 3.12 Tampilan utama 
JURNAL NUANSA INFORMATIKA

Volume 14 Nomor 2, Juli 2020

2. Proses Pendaftaran

Proses pendaftaran digunakan oleh user pelamar yang akan menggunakan sistem. Proses pendaftaran dimulai dengan mengklik menu pendaftaran, berikut ini tampilan form pendaftaran :

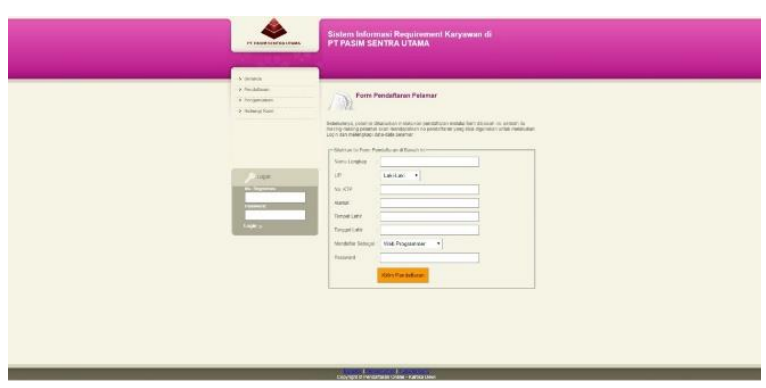

Gambar 3.13 Halaman Pendaftaran

3. Proses Login

Proses login digunakan oleh setiap user yang akan menggunakan aplikasi. Proses login dimulai dengan masuk halaman utama, berikut ini tampilan form login :

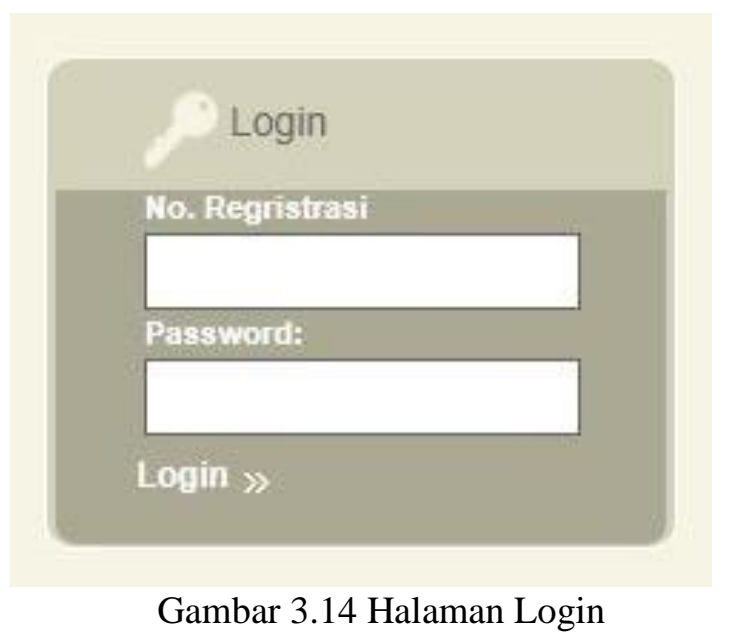

\section{Form Kelengkapan Data}

Setelah pendaftaran sukses dan pelamar login dengan menggunakan nomor registrasi dan password, maka pelamar akan menemukan halan yang menampilkan form kelengkapan data, form ini berisikan data diri yang sebagian sudah diisi ketika melakukan pendaftaran. Sisanya, pelamar akan menginputkan data dirinya pada menu ini. Berikut tampilan form kelengkapan data :
p-ISSN : 1858-3911, e-ISSN : 2614-5405

https://journal.uniku.ac.id/index.php/ilkom

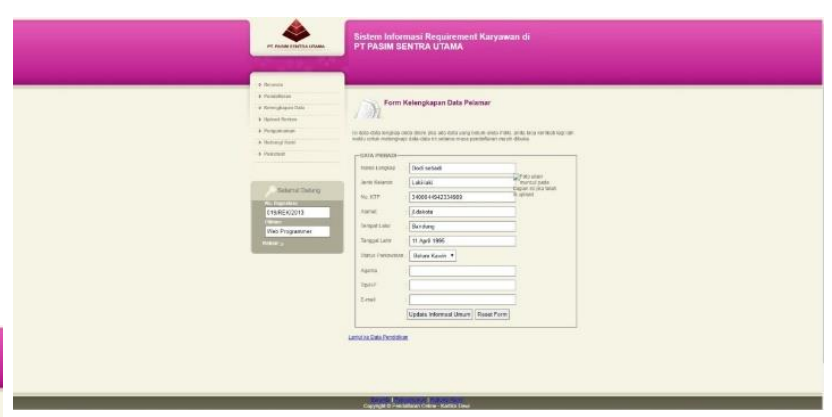

Gambar 3.15 Halaman Kelengkapan Data

5. Proses Upload Berkas

Proses upload berkas adalah proses mengunggah data-data yang menjadi persyaratan bagi pelamar kerja untuk melamar pekerjaan. Menu upload berkas ini hanya berlaku untuk user dengan hak akses pelamar. Proses ini dimulai dengan mengklik menu upload berkas. Berikut ini tampilan utama dari menu upload berkas :

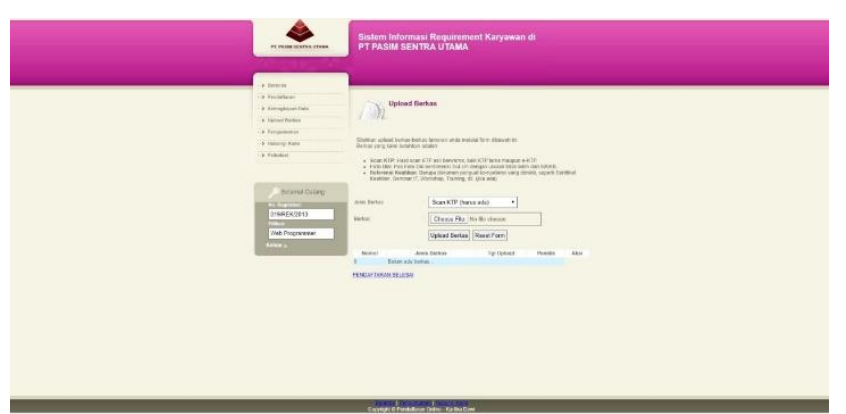

Gambar 3.16 Tampilan Menu Upload Berkas

\section{Halaman Menu Utama Sistem Rekrutmen Bagian Admin \\ Pada menu ini admin dapat melihat statistik jumlah pelamar yang telah melamar pekerjaan untuk beberapa posisi. Berikut tampilan dari menu utama bagian admin :}


JURNAL NUANSA INFORMATIKA

Volume 14 Nomor 2, Juli 2020

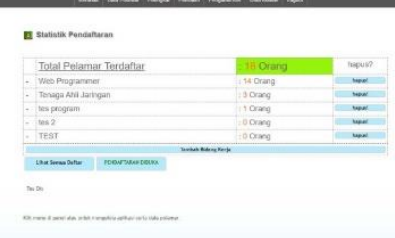

Gambar 3. 17 Tampilan Menu Utama bagian Admin

\section{Daftar Pelamar}

Menu daftar pelamar ini berlaku untuk user dengan hak akses admin. Proses ini dimulai dengan mengklik menu data pelamar. Berikut ini tampilan dari menu daftar pelamar :

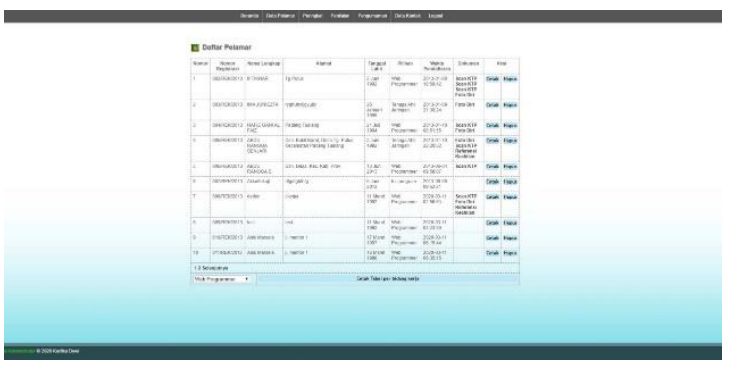

Gambar 3.18 Tampilan Daftar Pelamar

\section{Menu Pengumuman}

Menu pengumuman ini berlaku hanya untuk user dengan hak akses admin. Pada menu ini admin dapat membuat pengumaman untuk peserta yang gagal dan peserta yang lulus serta pengumuman umum. Berikut ini tampilan utama dari menu pengumuman :

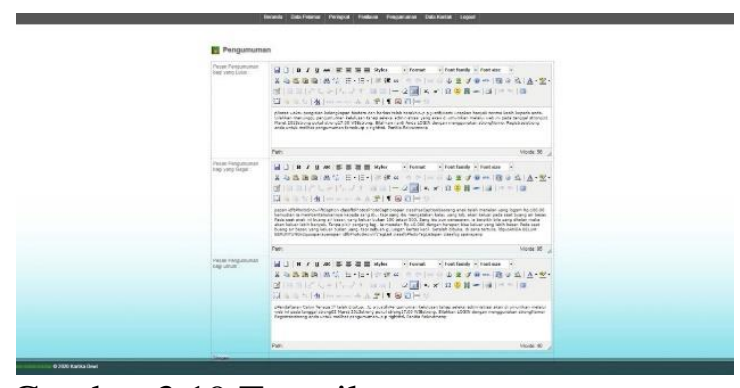

Gambar 3.19 Tampilan menu pengumuman

\section{KESIMPULAN}

Dari hasil analisis dan Perancangan Sistem Informasi Rekrutmen Karyawan PT. Pasim Sentra Utama maka dapat disimpulkan beberapa poin sebagai berikut : 1. Sistem yang berjalan saat ini dirasakan
p-ISSN : 1858-3911, e-ISSN : 2614-5405

https://journal.uniku.ac.id/index.php/ilkom

masih memiliki hambatan dalam pelayananan rekrutmen karyawan yang belum optimal, pelamar harus bolak-balik datang ke kantor untuk menyerahkan dokumen.

2. Analisis sistem yang dilakukan oleh peneliti pada sistem rekrutmen yang berjalan saat ini menemukan beberapa permasalahan diantaranya seleksi berkas lamaran membutuhkan waktu yang lama karena harus menyeleksi berkas lamaran satu persatu, hilangnya berkas lamaran karena berkas hanya disimpan pada lemari tanpa penggandaan ke dalam dokumen digital.

3. Setelah menganalisa hambatan-hambatan yang ada, maka penulis membuat pembangunan sistem informasi rekrutmen karyawan secara online yang dapat menghasilkan informasi yang lebih cepat. Mempermudah pelamar dalam pendaftaran dan memonitor informasi penerimaan kerja dimanapun pelamar berada. Dapat meminimalisasikan ketidak lengkapan persyaratan pelamar saat melakukan pendaftaran.

4. Karena lamanya waktu yang dibutuhkan untuk seleksi berkas, maka penulis membangun sistem informasi yang dapat memudahkan pihak perusahaan melakukan pengambilan keputusan dalam menerima karyawan baru.

5. Pembuatan sistem informasi rekrutmen karyawan karyawan berbasis web lebih efisien menggunakan framework CI dibandingkan dengan membuat sistem informasi dengan menggunakan php biasa tanpa framework.

6. Sistem Informasi ini dapat menyediakan ujian psikotes secara online, sehingga memudahkan para pelamar untuk melakukan ujian tersebut dimanapun. Serta penilaian yang sudah terotomatisasi membuat perusahaan tidak memerlukan waktu lagi untuk memeriksa hasil psikotes pelamar kerja.

\section{SARAN}

1. Dalam pengembangan lebih lanjut agar sistem rekrutmen karyawan ini dapat 
JURNAL NUANSA INFORMATIKA

Volume 14 Nomor 2, Juli 2020

diintegrasik dengan sistem informasi kepegawaian sehingga dapat mempermudah pengolahan data.

2. Jika terdapat kekurangan pada sistem yang diusulkan, hendaknya dicatat oleh user atau orang yang akan bersangkutan dengan sistem ini, hal ini ditujukan untuk perbaikan sistem agar menjadi lebih sepurna

3. Tersedianya versi mobile sehingga dapat mempermudah pelamar untuk melakukan proses lamaran kerja.

\section{DAFTAR PUSTAKA}

[1] Adi Nugroho. 2010, Rekayasa Perangkat Lunak Berbasis Objek dengan Metode USDP, Penerbit Andi, Jogjakarta.

[2] Alim Sumarno. 2012, Perbedaan Penelitian dan Pengembangan Elearning UNESA, Surabaya

[3] Edhy Sutanta. 2003, Sistem Informasi Manajemen. Yogyakarta, Graha Ilmu.

[4] George M.Scott, 2001, P. PrinsipPrinsip Sistem Informasi Manajemen: PT. Gramedia Pustaka Utama, Jakarta

[5] Hanif Al Fatta. 2007. Analisis dan Perancangan Sistem Informasi, ANDI Yogyakarta.

[6] Jogiyanto HM., MBA., Akt., Ph.D. 2005, Analisis \& DESAIN Pendekatan tersruktur teori dan praktek aplikasi bisnis. ANDI, Yogyakarta.

[7] Husein Hamdan. 2018. Pembelajaran Berbasis, WEB Dengan Moodle Versi 3.4 .

[8] Marakas. 2006, Management Information System. new york: McGraw-Hill Inc.
p-ISSN : 1858-3911, e-ISSN : 2614-5405

https://journal.uniku.ac.id/index.php/ilkom

[9] Pressman, Roger. 2005, Software Engineering, A Practitioner's Approach. New York, McGraw-Hill.

[10] M. Syafii. 2004, Membangun Aplikasi

Berbasis PHP dan My SQL. Yogyakarta, Andi. 